\title{
Implementation of BASEL-II in the Banking Industry (A Case study of Pakistani Banks)
}

\author{
Fiaz Ahmad \\ M.Abdus Salam
}

\begin{abstract}
Banking industry is exposed to different type of risks like credit, operational, interest rate risk, liquidity risk, foreign currency risk, compliance risk, reputational risk, and country risk. Banking industry can only become stable and stronger if they have proper tools to mitigate these risks. Due to product innovation and complexity of operations banks are giving more importance to mitigate these types of risks. Regulators (SBP) are emphasizing banks to develop their tools in order to control these risks. BASEL-Il is a basic tool which is used internationally in banking sector to mitigate these risks. Our study is focused on the implementation of BASEL-II in Pakistani Banking Industry. Researcher has analyzed that its implementation will bring positive effect in the Pakistani banking industry. Moreover what are the basic challenges banks are facing during its implementation. Data have been collected from fifteen banks a combination of Large, Medium, Small, Islamic and foreign banks operating in Pakistan selected on random basis. Results are analyzed through Pie Charts. This research will be helpful for the banking professional especially associated with risk management division and working towards the implementation of BASEL-II. Basel-II is still in the phase of implementation in the Banking industry in Pakistan. This research will provide the base to those want to study the after implementation effects of Basel-II in the Banking industry.
\end{abstract}

Keywords: Banking Industry, BASEL-II, Risk Management

\section{1- Introduction}

\subsection{Background of the Study}

Banking sector of any country is the backbone of its economy. A strong Banking sector of any country represents the strong economy. With growing complexity of operations and product innovations, financial institutions have progressively become more exposed to a diverse set of risks. These risks stretch from credit risk to interest rate risk, liquidity risk, foreign currency risk, strategic risk, compliance risk, reputational risk, country risk (taking international exposure) and operational risk.

The past two decades have witnessed significant developments in the field of risk management. Basel II Accord, first of all, aims to align banks' capital with their basic risk. It exploits effectively the new frontiers of risk management. (Akhter, 2006).

Fiaz Ahmad is an MS student at SZABIST, fiaz_ask@yahoo.com M. Abdus Salam is Assistant Director, Statistics \& Data Warehouse Department, State Bank of Pakistan, Muhammad.abdussalam@sbp.org.pk 


\subsection{Problem Statement}

It has to be acknowledged at the outset that one cannot dispute the inevitability of risks, and different type of risks, in bank operations

The researcher wants to study the challenges and implementation of BASEL-II in the banking Industry. The main objective of the report is to analyze that "What type of challenges face the banking Industry in the implementation of BASEL-II'.

\subsection{Research Objectives}

The Objectives of the research are as under

1 An overview of the banking Industry in Pakistan.

2 In-depth study of different pillars of BASEL-II including Credit risk, Market risk and operational risks.

3 To evaluate whether the Implementation of BASEL-II is useful instrument for mitigation of different type of risks associated with the banking Industry.

4 What Type of problems banks are facing in implementation of BASEL-II? Are Pakistani Banks having sufficient sources for the implementation of BASEL-II?

5 Will the implementation of BASEL-II result in mergers of small Pakistani Commercial Banks?

6 Is the implementation of BASEL-II a threat for the employees for loosing the job?

7 Is the implementation of BASEL-II will cause more difficulties for the SME sector to avail the credit facilities from Pakistani banks?

\subsection{Research Methodology.}

The research is qualitative in nature and an in-depth study of the BASEL-II will be carried out. A comprehensive study will be done to highlight the issues, challenges and implications of BASEL-II implementation in the banking Industry. A questionnaire will be developed and circulated in risk/credit management departments of Pakistani banks and the results will be analyzed selected on random basis.

\section{2- Banking Sector in Pakistan}

\subsection{Overall Performance of the Banking Sector}

The banking sector has performed well in last few years; banking sector profitability has broken its own records year after year till 2007.

\subsection{Banking Spreads}

Empirically, banking spread is widely used to quantify the cost of intermediation. This difference between the lending rate and borrowing rate is commonly known as the banking spreads.

\subsection{Profitability and Financial Soundness of the Banking System}

Profitability and soundness of the banks remained impressive and Pakistan's performance indicators in this area are amongst the best in its regional peers. The profits of the commercial banks crossed over US\$ 1 billion for the first three quarters of the year 2006. Assets of the Banks rose from negative 0.2 to 2.1 and return on equity from negative $3.5 \%$ to $26.1 \%$. 


\subsection{Consolidations and Foreign Investments in Banking Sector}

Consolidations of banking sector helps to develop a stronger and robust banking system. SBP fix the capital requirement of Rs. 13.00 BN up to year 2013.

\subsection{The Scope of Enhancement of Banking Business}

Today, penetration ratio of financial services is low, judged by any measure. Hence large portion of population is not availing banking facilities. This shows that there is a lot of potential in the banking industry.

\subsection{Role of SBP in Banking Sector}

State Bank of Pakistan is the regulatory authority for the banking sector and it has separate guidelines for the Corporate, SMEs, Consumers, Microfinance, Agriculture Financing and Export Financing.

\subsection{Present Scenario in the Banking Industry}

The results of the Banking industry for the year 2008 remained much below the expectations due to the present economic recession in the world. Some small banks have also shown losses and the profits of the bigger banks remained lower. The collapse of Karachi Stock Exchange also affected the banking industry. Due to the present economic recession it is feared that ratio of NPLs will be increased which will effect the profitability in 2009 as well.

\section{3- BASEL-II Accord}

\subsection{History of BASEL-II Committee}

The Basel Committee on banking Supervision was established as the Committee on Banking Regulations and Supervisory Practices by the central-bank Governors of the Group of Ten countries at the end of 1974 in the aftermath of serious disturbances in international currency and banking markets (notably the failure of Bankhaus Herstatt in West Germany). The first meeting took place in February 1975 and meetings have been held regularly three or four times a year since. (www.bis.org)

\subsection{From BASEL-I to BASEL-II}

The Basel I had a number of flaws. For instance, it provided "one size fit all" approach and did not differentiate between assets having less risk and assets having higher risk. Basel II provides incentive to banks having good risk management and punishes those that are not managing their risk profile appropriately by requiring higher capital.

\subsection{Introduction to BASEL-II}

As a result of their day-to-day activities, banks are exposed to different types of risk. Risk is the likelihood that an event will cause a bank to suffer losses.

Three Pillars of BASEL-II Accord

- Pillar 1 (Minimum Capital Requirements) provides guidelines to calculate the minimum capital that supervisors require a bank to hold to cover its credit, market and operational risks. This is called "minimum regulatory capital." 
- Pillar 2 (Supervisory Review) provides guidelines to assess a bank's capital adequacy. It starts with the calculation of the capital that a bank itself thinks it should hold at a minimum to cover all its risks, not only the Pillar 1 risks. This is usually called "economic capital."

- Pillar 3 (Market Discipline) provides guidelines for the disclosure to the outside world of information about a bank's risks and its available capital to offset unexpected losses associated with these risks.

\subsection{Type of Risks Associated with Banking Industry. \\ - Credit Risk \\ - Operational Risk \\ - Market Risk \\ - Interest rate risk in the Banking Book \\ - Liquidity Risk \\ - Other risks}

\subsection{Risk Management and Measurement}

Three options are available to allow banks to choose an approach that seems most appropriate towards bank's activities and controls. In order of increasing sophistication and risk sensitivity these options are:

- Standardized Approach;

- Foundation Internal Ratings Based (FIRB) Approach

- Advanced Internal Rating Based Approach (AIRB).

\subsection{Credit Risk Measurement ( Capital Adequacy Ratio)}

When risks materialize in the form of bad loans that cannot be recovered, the banks have to write off those loans. The capital adequacy ratio is the central feature of Basel Capital Accord. Capital adequacy ratios ("CAR") are a measure of the amount of a bank's capital expressed as a percentage of its risk weighted exposures i.e. T1+T2+T3/RWA. When using risk weighted assets, $\mathrm{T} 1+\mathrm{T} 2+\mathrm{T} 3 / \mathrm{RWA} \geq 8 \%$, a standard requirement of the regulator. $(\mathrm{T} 1=$ Tier 1 Capital, $\mathrm{T} 2=\mathrm{Tier} 2$ Capital, T3 = Tier 3 Capital)

\subsection{Operational Risk Measurement}

Basel II defines operational risk as "the risk of loss resulting from inadequate or failed internal processes, people and systems or from external events.

\section{Methods to Measure Operational Risk}

Basel Accord permits three methods for calculating operational risk capital charges in a continuum of increasing risk sensitivity:

- Basic Indicator Approach

- Standardized and Alternative Standardized Approach

- Advanced Measurement Approach (AMA).

\subsection{Market Risk Measurement}

Banks should have methodologies that enable them to assess and actively manage all material market risks, wherever they arise, at position, desk, business line and firm-wide level. (www.bis.org) 


\subsection{Internal Rate Risk in the Banking Book}

The measurement process should include all material interest rate positions of the bank and consider all relevant reprising and maturity data.

\section{Liquidity Risk}

Liquidity is crucial to the ongoing viability of any banking organization. Banks' capital positions can have an effect on their ability to obtain liquidity, especially in a crisis. Each bank must have adequate systems for measuring, monitoring and controlling liquidity risk.

\section{Other Risk}

Although other's risks, such as reputational and strategic risk, are not easily measurable, it expects industry to further develop techniques for managing all aspects of these risks.

\section{Implementation of BASEL-II}

All the banks are in the process of implementation of BASEL-II as it is the requirement from State bank of Pakistan to implement BASEL-II accord.

We have distributed the questionnaire among fifteen banks. A mix sample of large, medium, small size banks are included. Two foreign banks operating in Pakistan are also included evaluating their approach in Pakistani environment. Moreover, two Islamic banks are also included in the sample.

\subsection{Data Analysis}

Data are taken from fifteen commercial banks out of thirty-nine commercial banks which also include Islamic banks as well as foreign banks operating in Pakistan. We have selected following banks for data collection detailed as under

- Five major commercial Banks

- Six Medium sized Commercial banks

- Two Small Commercial banks

- Two Islamic Banks

- Two Foreign Banks Operating in Pakistan

- Questionnaire contains fifteen questions; most of them are closed ended.

Results are analyzed and presented in the form of Pie Charts detailed as under:

- Question No.1

Question No. 1 was related to analyze the impact of implementation of BASEL-II in the banking industry, results remained as under:

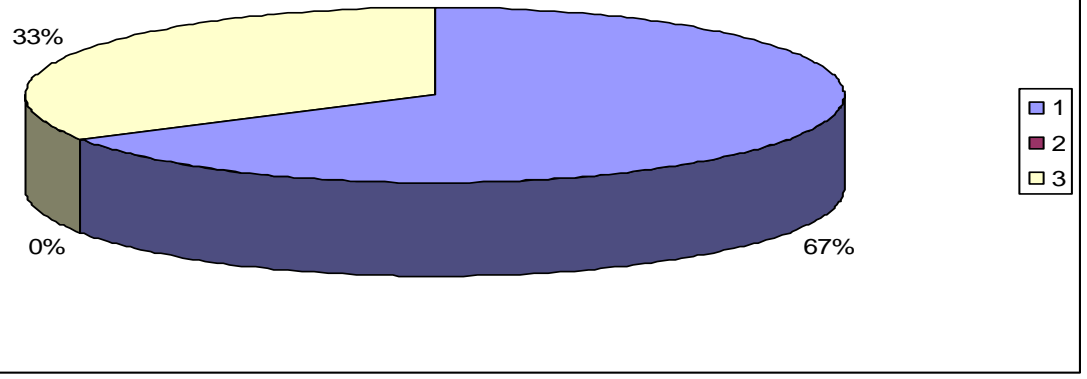


$67 \%$ banks responded that implementation of BASEL-II will bring positive impact in the banking industry, $33 \%$ says that it will take time to analyze that either BASEL-II will bring positive impact in the banking industry or not. No one says that its implementation will not bring any impact on the banking industry.

\section{- Question No.2}

Question two relates to most critical factor which is necessary for the implementation of BASEL-II. Results are shown as under:
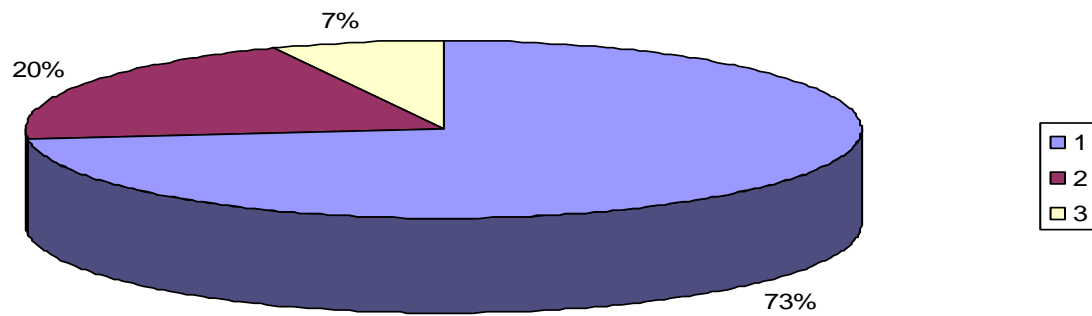

$73 \%$ of the respondents give more importance to reliable data as most important factor for the implementation of BASEL-II, $20 \%$ says industry expertise, while $7 \%$ were in the favor of latest technology.

\section{- Question No.3}

Question no. 3, was related to availability of reliable data for the implementation of BASEL-II. Results are as under:

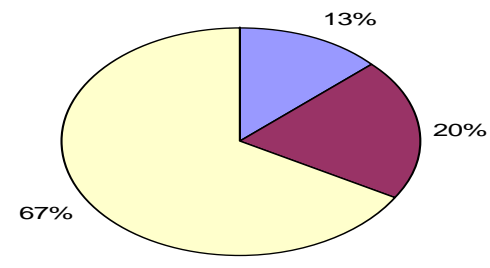

$67 \%$ of the banks said yes about the availability of the reliable data, $20 \%$ said no, while other $13 \%$ said that it will be developed with the passage of time.

\section{- Question No.4}

Question No. 4 was that either the banks have sufficient resources to bear the cost of the implementation of BASEL-II. Results are as under: 


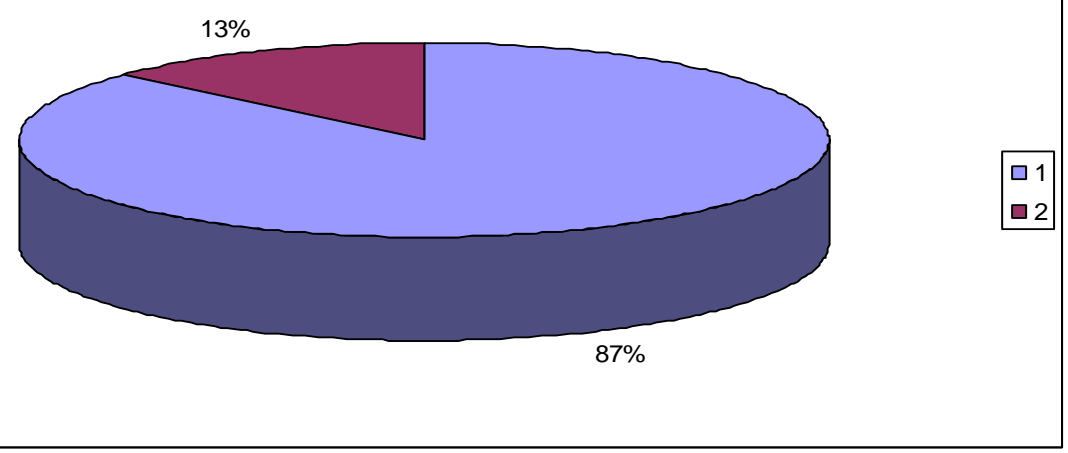

$87 \%$ of the banks said that they have sufficient resources for the implementation of BASEL-II , while other $13 \%$ which mainly includes small banks showed unavailability of the resources for the implementation of BASEL-II.

- Question No.5

Question No. 5 was related to industry expertise which is required for the implementation of BASEL-II. Results are shown in the following pie chart.

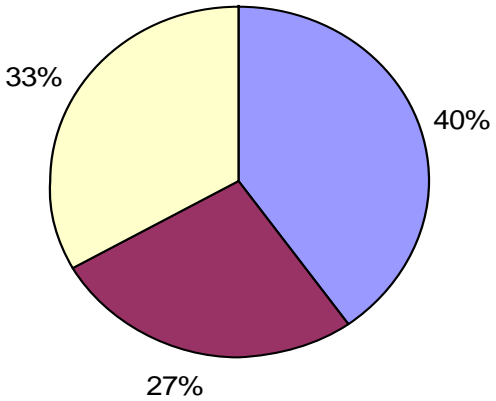

$40 \%$ of the banks said that they have expert persons for the implementation of BASEL-II, $27 \%$ said no, while other $33 \%$ says that they will hire the expert persons from outsourcers.

\section{- Question No.6}

Question No.6 was asked that either the implementation of BASEL-II was supported by the upper management and Board of Directors. Results are as under:

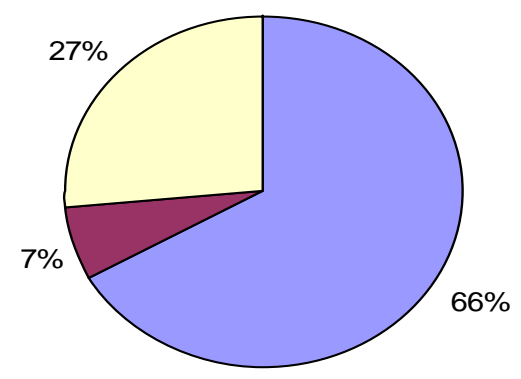


$66 \%$ results shows that it is supported by the top management and Board of Directors, $7 \%$ said no, while $27 \%$ said that they are supporting its implementation due to the pressure of SBP.

\section{- Question No.7}

Question no. 7 asked that either the Banks which will implement the BASEL-II will have a competitive edge results are as under:

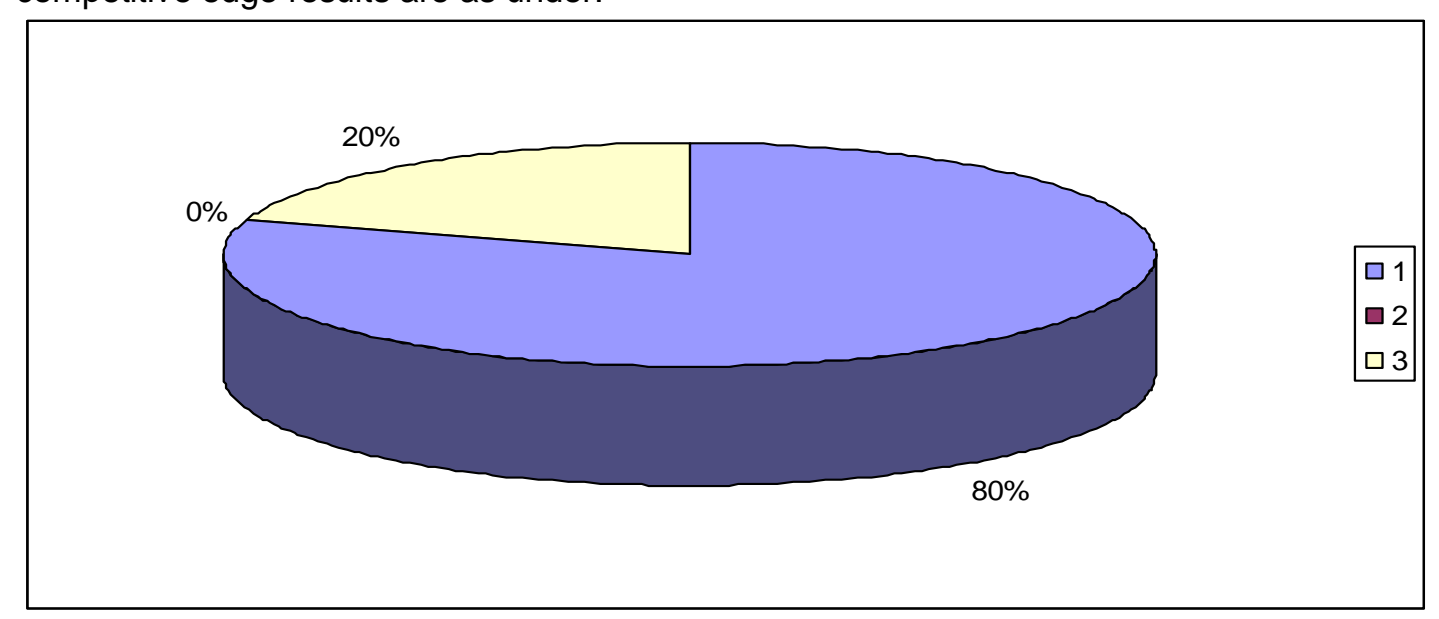

$80 \%$ of the respondents were in the favor while only $20 \%$ said no.

\section{- Question No.8}

In question no.8, we asked about the most important risk which is covered under the BASEL-II. Results are as under:

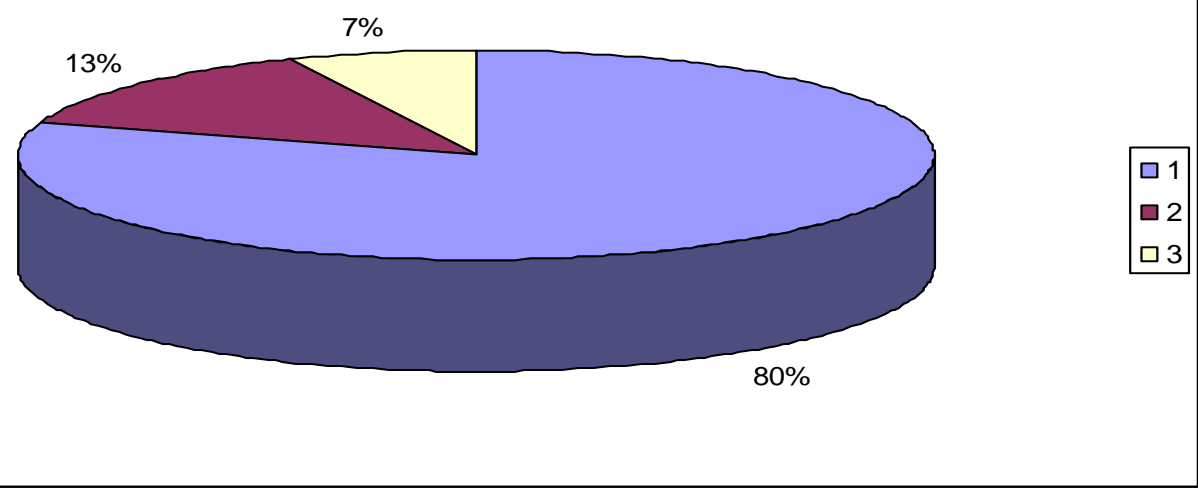

$80 \%$ of the respondents said that Credit Risk is the most important risk which is covered under the BASEL-II, $13 \%$ were in the favor of operational risk while only $7 \%$ favored the market risk.

- Question No.9

Question No. 9 was asked that either the banks will develop their own models to cover the different type of risks. Results remained as under: 


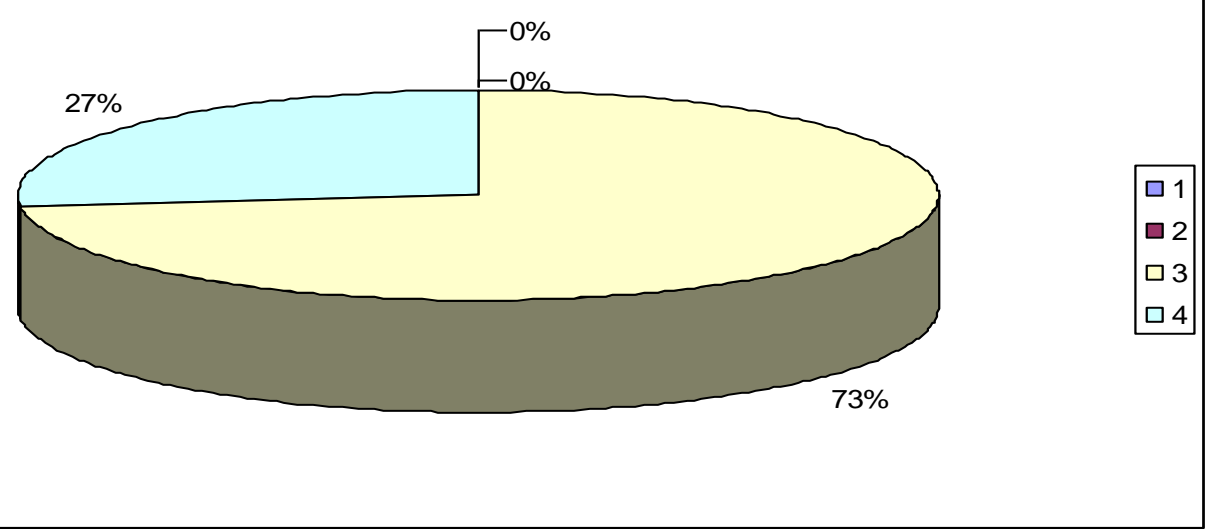

$73 \%$ of the respondents said that they will develop their own models but as per the guidelines provided in the BASEL-II, while $27 \%$ said that they will rely on the models provided by SBP.

- Question No.10

Question no. 10 was asked that either the implementation of BASEL-II will result in the merger of small banks. Results are as under:

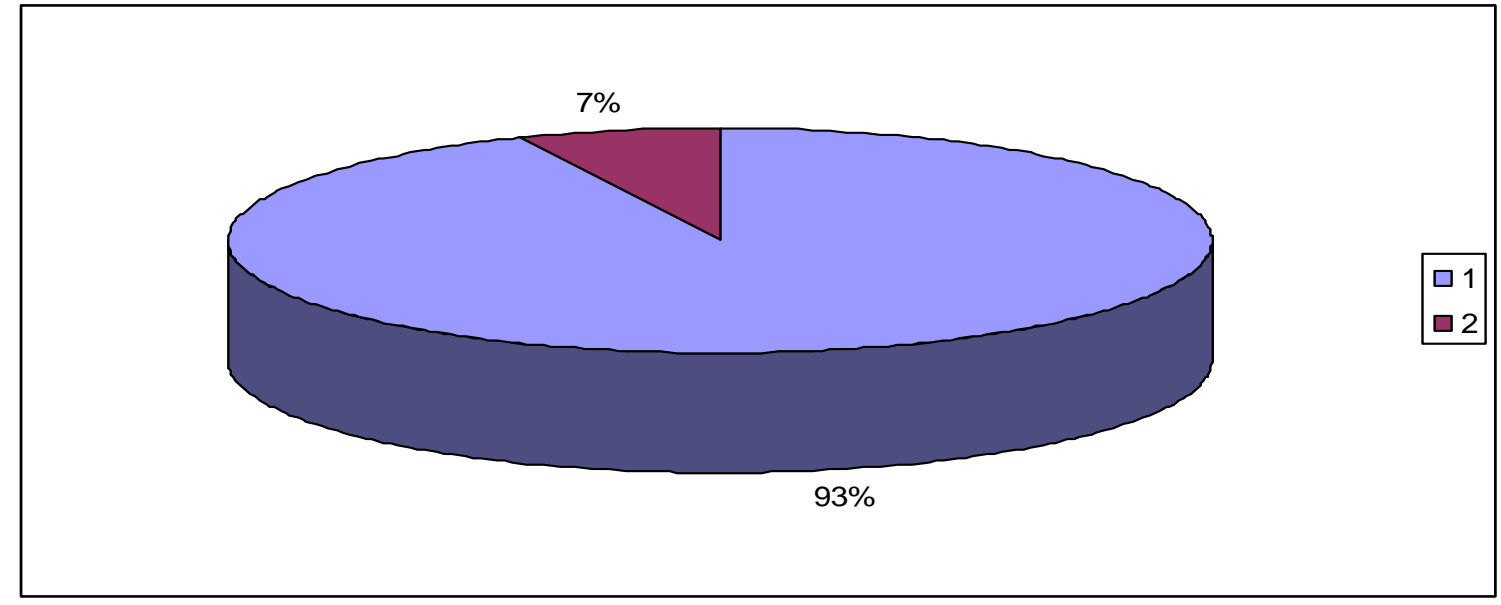

$93 \%$ said that it will result in the merger of small banks, while only $7 \%$ said no.

- Question No.11

Question no .11 asked that either the implementation of BASEL-II will create more difficulties to avail the credit facilities from the bank. Results are as 
under:

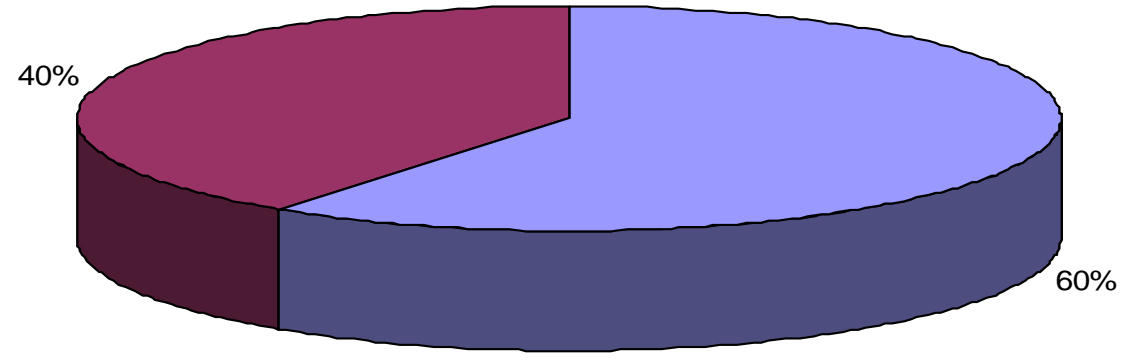

$60 \%$ said yes that it will create difficulties for SMEs to get financing from the banks, while $40 \%$ said it will not affect the SME sector.

\section{- Question No.12}

Question no. 12 was related to the approach which is presently followed by the banks, results are shown below:

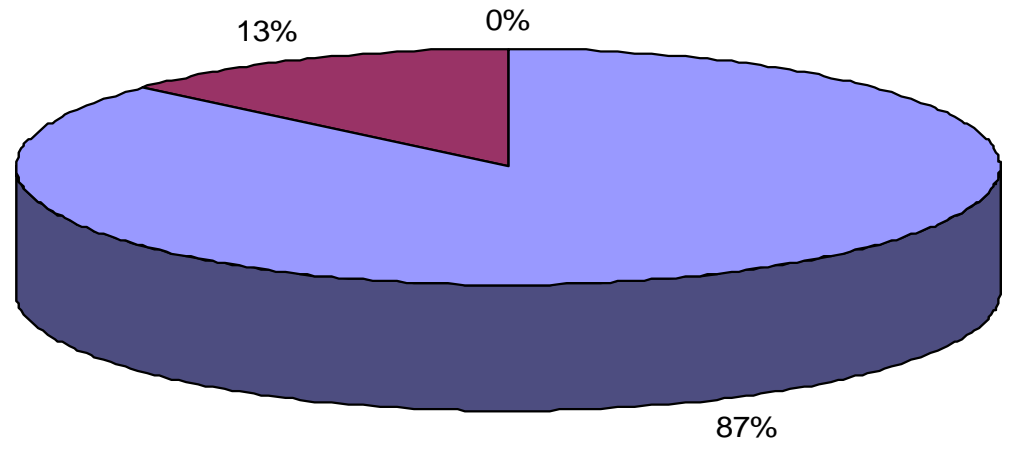

$87 \%$ of the banks are presently following the standardized approach, while $13 \%$ are following the FIRB approach; no one is presently following the AIRB approach.

- Question No.13

Question no.13 was that 'which approach will be suitable for your bank.' Results are as under: 


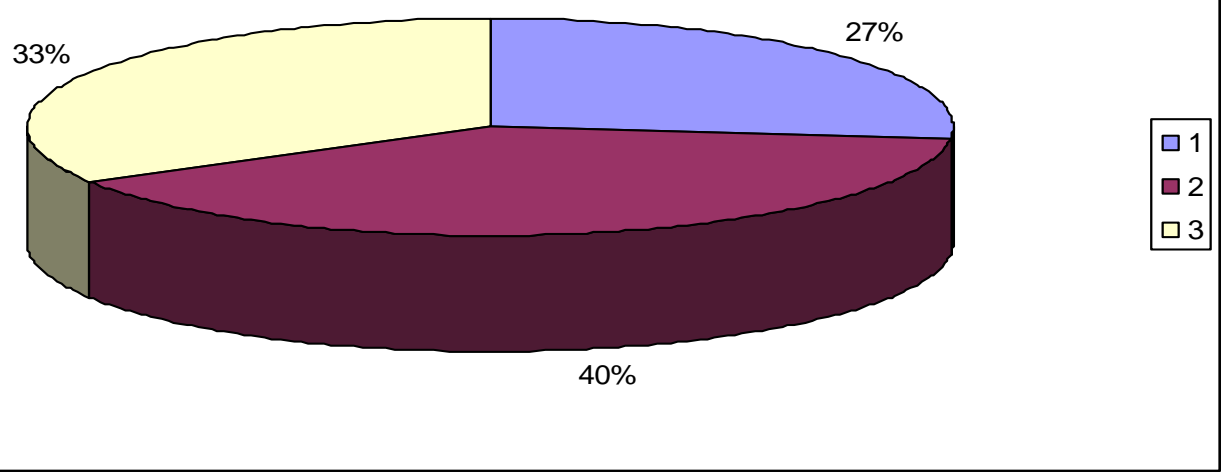

$40 \%$ said that it will be FIRB approach, $27 \%$ said it will be standardized approach, while $33 \%$ said it will be advanced approach.

- Question No.14

Question No 14 asked that either your bank has proper risk management set-up to cover all risks, results are as shown

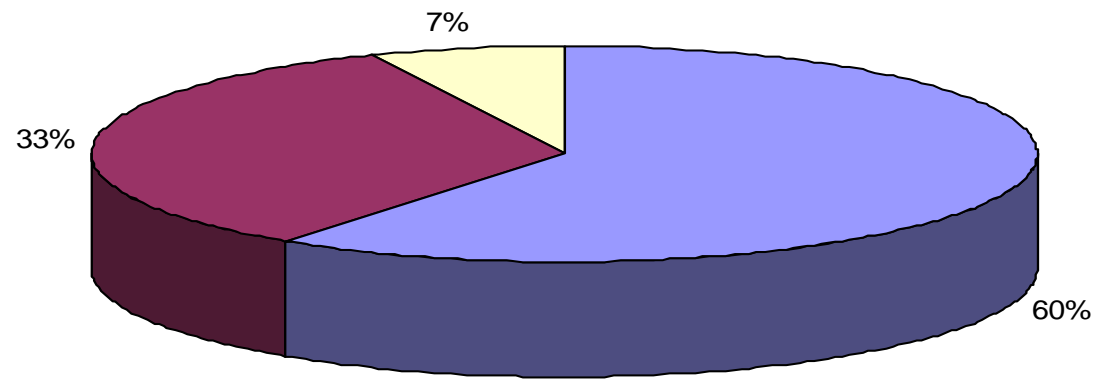

$60 \%$ said yes, 33\% said no, while other $7 \%$ said partially.

\section{- Question No.15}

Question no 15 was asked about the deadline of implementation of BASEL-II. Results are as under:

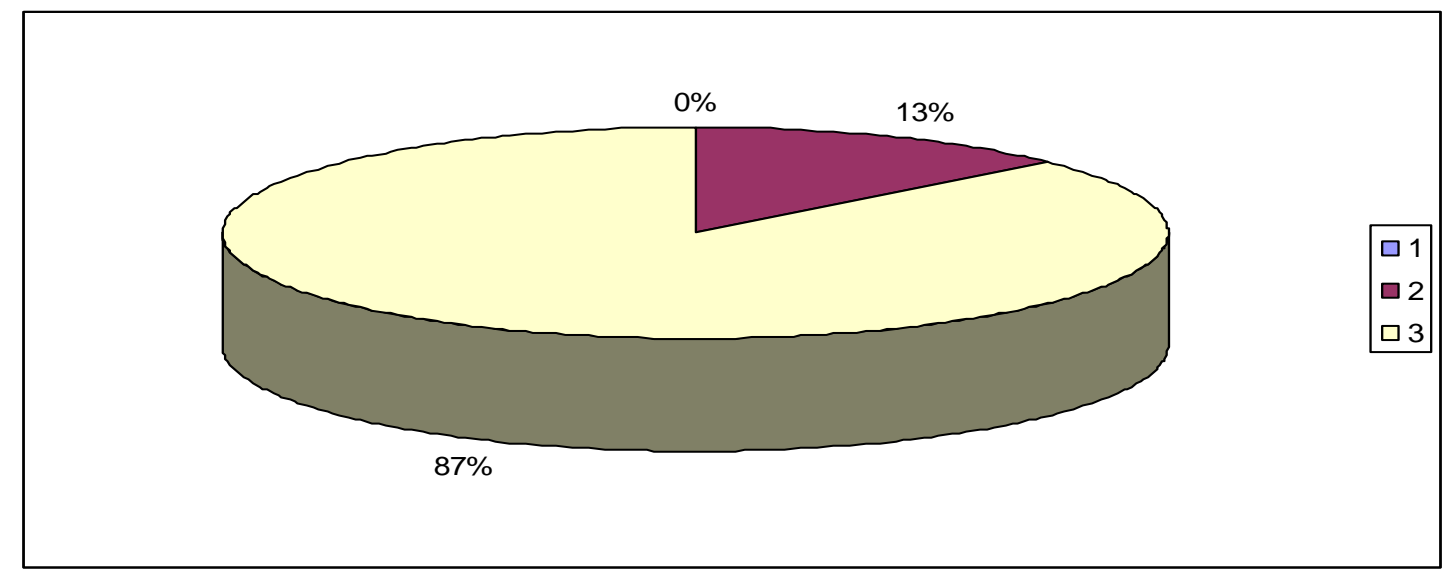


$87 \%$ were not sure about the deadline of BASEL-II. While only $13 \%$ say it is in 2013.

\section{Conclusion}

With this tremendous growth and product innovations, banks are also exposed to many type of risks. The basic purpose for the implementation of BASEL-II is to cope with different risks associated with the banking industry. Our research was focused on that either the BASEL-II is useful instrument for mitigating the risks in banking industry. Moreover, we have also study different issues in implementation of BASEL-II in Pakistani banks.

We have analyzed the results and found that most of the banks (67\%) included in our sample agreed that implementation of BASEL-II will bring positive impact in the banking industry, $33 \%$ said that the results will be evaluated after its implementation. But the results show that its implementation will require reliable data, industry expertise and cost of technology for the implementation of the BASEL-II in the banking industry. Without these important ingredients the implementation of BASEL-II and its effectiveness to mitigate the risks will remain question mark. We have come to know through our results that banks have rated the most important risk of banking industry as credit risk. The banks are more worried to mitigate the credit risk in order to secure their Bank's Credit portfolio.

We have also tried to evaluate the negative impacts of implementation of BASEL-II and $93 \%$ results show that its implementation will result in merger of small banks who are not able to bear the cost of technology and to enhance their capital as per BASEL-II requirement. Moreover, $60 \%$ results also show that its implementation will create more difficulties for SMEs sector to avail the credit facilities from the banking industry.

Results also show presently the banks are at initial stage of implementation of BASEL-II and they are following the initial approach to mitigate the risks.

\section{Recommendations}

We would like to highlight few recommendations which may play useful part in its implementation:

- In order to get more reliable data, banks should give more focus in terms of expert staff at branch level.

- Banks should develop such models which will not affect the SMEs sector for availing the credit facilities.

- Banks are focused to credit risk as the other risks are equally important and these risks should also be properly addressed.

- Those banks that are in the favor of hiring industry expertise from outsourcers should focus on developing their own expert staff in order to keep things confidential.

- While developing new products in banking industry, risk factors as per BASEL-II should be considered. 


\section{References}

Dr. A.Zia, Shahid [ July 4,2005], The Nation's bank, The Nation, Karachi, Business Section.

Ahmed Rizvi, Shamim [2006], Banking Sector to retain Growth Momentum in 2006, Pakistan and Gulf Economist.

Dr. Akhtar, Shamshad, [September 2006] BASEL-II implementation, Issues Challenges and implications, addressed at Institute of Bankers of Pakistan.

Brigham, Eugene, Financial Management theory and Practice, The Dryden Press

Khan, Muzzam , Performance of banking sector in 2005, Money and Business of Pakistan, 2006.

Khawaja, Al farid, Banking sector new themes and outlooks,[2006] Pakistan and Gulf Economist. Ministry of Finance, Government of Pakistan [2007], Update on Pakistan's Economy, Islamabad.

National Bank of Pakistan [2006], Annual Reports, 2005-2006, Karcahi.

NBP Economic Bulletin, Banking Sector Performance, [August, 2006], Vol. 33, No. 4, Karachi, Pakistan.

State bank of Pakistan [2005], Financial sector Assessment (FSA), Karachi.

Van Horne, James C, Fundamentals of Financial Management, $9^{\text {th }}$ Edition, Practice Hall, INC

www.bis.org accessed on 24-02-2009

www.sbp.org.pk accessed on 24.02.2009

www.ibp.org.pk accessed on 24.02.2009 